\title{
Health impact assessment of exposure to transport emissions in Flanders: methodology study
}

\author{
S. Dhondt \& L. Hens \\ Human Ecology Department, Vrije Universiteit Brussel (VUB), Belgium
}

\begin{abstract}
Traffic is identified as one of the main contributors to ambient air pollution. New evolutions in exposure assessment provide both more accurate estimations of traffic exhaust concentrations and individual exposure concentrations. However current epidemiology and health impact assessment (HIA) methods are not yet capable of dealing with these new exposure evolutions. In this paper methods are explored to perform a HIA based on an activity-based traffic model. Based on the main traditions of a HIA a stepwise approach is presented, estimating the impact of particulate matter, benzene, ozone and nitrogen dioxide in two strategies. A first strategy serves as the core analysis while a second more expansive strategy, allows more uncertainty in assessing the impact of air pollution.
\end{abstract}

Keywords: air pollution, health impact assessment, traffic, methodology.

\section{Introduction}

Flanders, the Northern part of Belgium, is a highly dense region typified as one urban nebula, where individual car traffic dominates the coverage of regional movement requirements. Transport is one of the main contributors to the emissions of air pollutants, including particulate matter (PM) and nitrogen dioxide $\left(\mathrm{NO}_{2}\right)$. On average the contribution of transport to $\mathrm{PM}_{10}$ in Flanders is $28 \%$ and $35 \%$ for $\mathrm{PM}_{2,5}$ [1]. For $\mathrm{NO}_{\mathrm{X}}$ the share of traffic in 2002 was $44 \%$ of the total $\mathrm{NO}_{\mathrm{X}}$-emissions [2]. Recent research consistently indicates that outdoor air pollution harms health, and points to air pollution that stems from transport as an important contributor. Health impact assessments (HIAs) allow quantifying the effect of transport emissions on health [3-5]. However the number of HIAs on 
transport-related air pollution is rather limited. Main reason is that epidemiological information is still too inconsistent to derive a well-based exposure-response function, which is needed to quantify the health effects [6].

The current HIA relies on an activity-based model, producing more accurate emission estimates and individual dynamic exposure concentrations. However, current health impact assessment methods and epidemiology are not capable of dealing with these recent evolutions in exposure assessment. Therefore to be able to perform a HIA, possible answers are explored based on current epidemiologic and toxicological research. Main attention is given to the absence of traffic exposure-response functions and how to handle individual exposure estimations. A methodology is proposed on how the health-impacts of air pollution in Flanders based on a traffic model can be assessed. The main steps of a HIA serve as a guideline in the motivation of the methodological choices being made.

\section{Hazard identification}

Traffic is one of the main contributors to emissions of $\mathrm{PM}$ and $\mathrm{NO}_{\mathrm{X}}$. Ozone as a secondary pollutant formed by precursors including nitrogen dioxide, is also highly related to traffic emissions. Toxicological research identifies these three pollutants as having adverse effects on health [7-11], through inflammatory reactions on the lung tissue, which in turn promote blood clot formation and the constriction of blood vessels [12]. Benzene with a permissible volume up to 5\% in petrol, is a causative agent in the development of leukemia [13].

Notwithstanding the many uncertainties on the underlying processes that cause a health effect to occur, toxicology provides the biological plausibility of a causal relationship between traffic-related air pollution and health. Epidemiological research does not [6]. In HIAs pollutants, and more specific particulate matter, are therefore usually handled as a uniform pollutant, regardless the contribution from different sources, such as traffic, and thus assuming the same effect on health. This likely leads to an underestimation of the effects of local traffic emissions, since most epidemiological studies do not fully reflect the effects of exposure in hot spots near traffic [5] and the supposed higher toxicity of traffic related particle matter [14, 15]. Some studies [16] established a direct association between traffic and health, through looking at the distance between place of residence and nearby major roads. However the use of this risk estimate is not applicable into the current traffic model.

\section{Exposure assessment}

To obtain exposure concentrations an activity-based model (AB-model) is used. AB-models provide detailed Origin-Destination $(\mathrm{O} / \mathrm{D})$ matrices, by estimating activity-travel schedules for every individual or household. The model can predict which activities are carried out, where, with whom, when, how long, with which transportation mode and finally which route is followed [17]. By changing some parameters in the model, this information can be calculated for different circumstances. 
When this extensive information from is applied to a transportation network, detailed information about activity-related traffic flows on the different roads (e.g. average speed and amount of traffic) and total distances for each trip can be calculated. Based on pollutant-specific emission factors, these activity-related traffic flows on the different traffic links can then be converted into vehicle exhaust emissions. Combined with dispersion models this provides more accurate estimates on hourly ambient (traffic) pollutant concentrations [18]. Combining these pollutant concentrations with the simulated activity patterns from the AB-model, revealing each individual's location on a specific time, dynamic exposure estimates can be calculated for each individual. Preliminary results reveal large differences between the static and the dynamic approach, mainly pointing to an underestimation of exposure levels of the first [19].

However, both traffic pollution concentrations and dynamic exposure values offer challenges to current epidemiology. To counter the problem of traffic pollution concentrations, the estimated emissions from traffic are completed with emissions from other sources, such as industry and agriculture, taken from the national emission inventory [20]. By estimating the all-source exposure it is possible to use the existing ambient PM-estimates. The possibility to derive a traffic-attributable fraction of $\mathrm{PM}$ (both $\mathrm{PM}_{10}$ and $\mathrm{PM}_{2,5}$ ) from the emission-total after dispersion has yet to be researched. The calculation of such a fraction would however allow one to estimate the traffic attributable health effects [3].

For the problem of individual exposure estimates there is no straightforward answer to be found in current epidemiology. Epidemiology uses estimates of population exposure based on fixed monitoring sites and does not reflect the spatial and temporal variability of personal exposure [6]. Therefore this type of variability cannot be taken into account and only the static exposure estimates will be used. These exposure estimates are obtained from the immission data combined with demographic data in a geographic information system (GIS). GIS is used for the (spatial) integration of the different data and can be used to produce both maps of exposure and disease. Concentration data are plotted on a map into grid cells of $1 \times 1 \mathrm{~km}$, whilst demographic data are provided for every census tract, a geographical classification allowing more detail than the municipal level. There are 9.906 census tracts in Flanders and Brussels, compared to 327 municipalities. By combining both high spatial resolution concentration and demographic data, detailed concentration distribution maps and tables of Flanders and Brussels are obtained. By applying the agedistribution of the population within every census tract on the concentration data, special attention can be given to vulnerable groups such as children and elderly.

\section{Dose-response evaluation}

When assessing the effects of air pollution on health the WHO $[6,21]$ recommends assessing both cause- and age-specific mortality and morbidity. In this study both morbidity and mortality for respiratory and cardiovascular diseases will be calculated. For mortality, cancer is included as well: lung cancer due to (fine) particulate matter and leukaemia due to benzene. For morbidity, 
hospital admissions are the prior outcome, with specific attention to asthma and chronic bronchitis or chronic obstructive pulmonary disease (COPD).

When assessing age-specific health outcomes, there is still a great deal of uncertainty between a particular subgroup and the specific health effects: who is susceptible is dependent on the specific health end point being evaluated and the level and length of exposure [7]. Infants and elderly are identified to be particularly at risk.

Risk estimates or concentration-response functions are the main key to perform a HIA, as they link exposure estimates with health data to calculate the health outcomes. Due to their important role in a HIA there are some considerations to bear in mind when selecting the functions to be used, such as the use of estimates from meta-analyses. Especially within Europe such metaanalyses are being carried out [22]. In line with the APHEIS-project (Air Pollution and Health: a European Information System) [23] estimates were chosen from multi-centre studies, such as APHEA (Air Pollution and Health: a European Approach). This is in line with epidemiologic reasoning, giving more weight to the overall results of all adequately conducted studies rather than one single result [24]. Table 1 gives an overview of the different risk estimates selected. The estimates used in APHEIS are as much as possible adopted

It is important to bear in mind the distinction between the health effects of long term and short-term exposure. Hospital admissions are more than often related to short-term exposure, whilst mortality is both related to short- and longterm exposure, so the effects on mortality from both exposures will be calculated. For mortality however there has been a growing recognition that the effects of long-term exposure (expressed as years of life lost, YLL) are more meaningful $[3,25]$ and should be seen as the main effects [26]. The short-term effects (expressed in number of attributable cases) are only calculated to give a complete and more detailed view on the mortality effects [25, 27]. Because where short-term time series studies clearly show a relationship between ambient PM and mortality from respiratory causes, the long-term cohort studies do not [28]. The mortality effects of long-term and short-term exposure should however not be summed up.

\subsection{Short-term exposure estimates}

For the short-term effects of PM, the time series studies estimates for cardiovascular and respiratory mortality [29, 37] and hospital admissions [31, 32] within APHEA are adopted. They provide the most recent multi-centre metaanalyses and most robust estimates in Europe. For the elderly both cardiovascular mortality and hospital admissions for cardiovascular and respiratory diseases, such as chronic bronchitis, will be assessed. The estimates are adopted from the APHEA-project [30, 37] and the WHO meta-analysis [22]. For children only hospital admissions for respiratory diseases, including asthma, will be assessed based the short-term exposure estimates from the WHO metaanalysis [22]. 
Table 1: $\quad$ Overview of selected risk estimates (given as relative risks).

\begin{tabular}{|c|c|c|c|c|c|c|}
\hline & \multirow{2}{*}{ Health indicator } & \multirow{2}{*}{ Age group } & \multirow{2}{*}{ ICD 10} & $\mathbf{R R}$ & $(95 \% \mathrm{CI})$ & \\
\hline & & & & \multicolumn{3}{|c|}{ for a $10 \mu \mathrm{g} / \mathrm{m} 3$ increase } \\
\hline \multicolumn{7}{|c|}{ Attributable cases } \\
\hline \multirow{11}{*}{$\begin{array}{l}\text { PM10 very } \\
\text { short term }\end{array}$} & \multirow[t]{2}{*}{ Cardiovascular mortality } & all ages & I00-99 & 1,0076 & $1,0047-1,0105$ & {$[29]$} \\
\hline & & $>65$ years & $\mathrm{I} 00-50$ & 1,0070 & $1,004-1,010$ & {$[30]$} \\
\hline & Respiratory mortality & all ages & J00-99 & 1,0058 & $1,0021-1,0095$ & {$[29]$} \\
\hline & \multirow{2}{*}{$\begin{array}{l}\text { Cardiovascular hospital } \\
\text { admissions }\end{array}$} & all ages & I00-50 & 1,0050 & $1,002-1,008$ & {$[30]$} \\
\hline & & $>65$ years & $\mathrm{I} 00-50$ & 1,0070 & $1,004-1,01$ & {$[30]$} \\
\hline & \multirow[t]{3}{*}{ Respiratory hospital admissions } & all ages & J00-99 & 1,0114 & $1,0062-1,0167$ & {$[31]$} \\
\hline & & $<15$ years & J00-99 & 1,0100 & $0,998-1,021$ & {$[22]$} \\
\hline & & $>65$ years & $\mathrm{J} 00-99$ & 1,0070 & $1,002-1,013$ & {$[22]$} \\
\hline & \multirow[t]{2}{*}{ Asthma hospital admissions } & $15-64$ years & $\mathrm{J} 45-46$ & 1,0110 & $1,003-1,018$ & {$[32]$} \\
\hline & & $<15$ years & $\mathrm{J} 45-46$ & 1,0120 & $1,002-1,023$ & {$[32]$} \\
\hline & $\begin{array}{l}\text { Asthma and COPD hosp } \\
\text { admissions }\end{array}$ & $>65$ years & $\mathrm{J} 40-47$ & 1,0100 & $1,004-1,015$ & {$[32]$} \\
\hline \multirow{2}{*}{$\begin{array}{l}\mathrm{PM} 2,5 \\
\text { short term }\end{array}$} & Cardiovascular mortality & & I00-99 & 1,0130 & $1,005-1,021$ & {$[22]$} \\
\hline & Respiratory mortality & & J00-99 & 1,0110 & $1,002-1,020$ & {$[22]$} \\
\hline \multirow[t]{10}{*}{ O3 short term } & $\begin{array}{l}\text { All cause mortality (excl ext } \\
\text { causes) }\end{array}$ & all ages & A00-R99 & 1,0046 & $1,0022-1,0073$ & {$[33]$} \\
\hline & Cardiovascular mortality & all ages & I00-99 & 1,0040 & $1,0022-1,0073$ & {$[33]$} \\
\hline & Respiratory mortality & all ages & J00-99 & 1,0113 & $1,0074-1,0151$ & {$[33]$} \\
\hline & \multirow[t]{4}{*}{ Respiratory hospital admissions } & $15-64$ years & J00-99 & 1,0010 & $0,991-1,012$ & {$[22]$} \\
\hline & & $15-64$ years & J00-99 & 1,0310 & $1,013-1,049$ & {$[34]$} \\
\hline & & $>65$ years & J00-99 & 1,0050 & $0,998-1,012$ & {$[22]$} \\
\hline & & $>64$ years & J00-99 & 1,0380 & $1,018-1,058$ & {$[34]$} \\
\hline & \multirow[t]{2}{*}{ Asthma hospital admissions } & $15-64$ years & $\mathrm{J} 45-46$ & 1,0150 & $0,955-1,078$ & {$[35]$} \\
\hline & & $<15$ years & $\mathrm{J} 45-46$ & 1,0060 & $0,976-1,037$ & {$[35]$} \\
\hline & COPD hospital admissions & all ages & $\mathrm{J} 40-44, \mathrm{~J} 47$ & 1,0430 & $1,022-1,065$ & {$[36]$} \\
\hline \multirow{5}{*}{$\begin{array}{l}\text { NO2 short } \\
\text { term }\end{array}$} & Cardiovascular mortality & all ages & I00-99 & 1,0040 & $1,0029-1,0052$ & {$[11]$} \\
\hline & Respiratory mortality & all ages & $\mathrm{J} 00-99$ & 1,0038 & $1,0017-1,0058$ & {$[11]$} \\
\hline & \multirow[t]{2}{*}{ Asthma hospital admissions } & $15-64$ years & $\mathrm{J} 45-46$ & 1,0290 & $1,003-1,055$ & {$[35]$} \\
\hline & & $<15$ years & $\mathrm{J} 45-46$ & 1,0260 & $1,006-1,049$ & {$[35]$} \\
\hline & COPD hospital admissions & all ages & $\mathrm{J} 40-44, \mathrm{~J} 47$ & 1,0190 & $1,002-1,047$ & {$[36]$} \\
\hline \multirow{5}{*}{$\begin{array}{l}\text { PM10 } \\
\text { accumulative } \\
(40 \text { days })\end{array}$} & \multirow[t]{3}{*}{ Cardiovascular mortality } & all ages & I00-99 & 1,0197 & $1,0139-1,0255$ & {$[37]$} \\
\hline & & 65-74 years & I00-99 & 1,0206 & $1,0105-1,0309$ & {$[37]$} \\
\hline & & $>74$ years & I00-99 & 1,0235 & $1,0142-1,0329$ & {$[37]$} \\
\hline & \multirow[t]{2}{*}{ Respiratory mortality } & all ages & J00-99 & 1,0421 & $1,0109-1,0742$ & {$[37]$} \\
\hline & & $>74$ years & J00-99 & 1,0457 & $1,0125-1,0799$ & {$[37]$} \\
\hline \multirow{2}{*}{$\begin{array}{l}\text { PM10 long } \\
\text { term }\end{array}$} & Respiratory mortality & 1 month - 1 year & J00-99 & 1,2160 & $1,102-1,342$ & {$[38]$} \\
\hline & Infant mortality & 1 month - 1 year & A00-Y98 & 1,0480 & $1,022-1,075$ & {$[38]$} \\
\hline \begin{tabular}{|l|} 
NO2 long \\
term
\end{tabular} & Respiratory mortality & $55-69$ years & J00-99 & 1,3700 & $1,00-1,87$ & {$[39]$} \\
\hline \multicolumn{7}{|c|}{\begin{tabular}{|l|} 
Loss in life expectancy \\
\end{tabular}} \\
\hline \multirow[t]{3}{*}{ PM2,5 } & All cause mortality & $>29$ years & A00-Y98 & 1,0600 & $1,02-1,11$ & {$[40]$} \\
\hline & Cardiopulmonary mortality & $>29$ years & $\begin{array}{l}\mathrm{I} 10-70, \mathrm{~J} 00- \\
99\end{array}$ & 1,0930 & $1,033-1,16$ & {$[40]$} \\
\hline & Lung cancer mortality & $>29$ years & C33-34 & 1,1350 & $1,044-1,23$ & {$[40]$} \\
\hline Benzene & Leukaemia mortality & all ages & C91-95 & $6 \times 10-6$ & $4,4-7,5 \times 10-6$ & {$[41]$} \\
\hline
\end{tabular}

The effects of ozone will be assessed for short-term exposure only. As Flanders (including Brussels) has a moderate climate, high ozone concentrations only occur during summer. So contrary to the recommended estimates of the WHO [22, 42] which are all-year estimates, the estimates from Gryparis et al. [33] are adopted, which assess both all-cause mortality (including asthma and 
COPD) and cause specific mortality during summer only. The recommended estimates by the WHO [22, 42] for hospital admissions for respiratory causes are slightly insignificant, therefore two studies from APHEA1 will be adopted as well [34, 36], however with greater uncertainties than the proposed metaanalysis, due to the limited cities where the studies are based on.

Epidemiological risk estimates of nitrogen dioxide are uncertain and are therefore treated last. This is mainly due to the inability to derive effects independent from other pollutants in the air pollution mix. However within APHEA2 a relationship between cause-specific mortality could be found [11]. For hospital admissions for asthma and COPD the studies from APHEA1 were adopted $[35,36]$.

\subsection{Long term exposure estimates}

For long-term exposure effects of PM, the estimates from cohort studies are used $[39,40,43]$. However these and the more recent and extended studies [28, 44] do not find an association respiratory mortality. Nonetheless the estimates of the original cohort study from Pope et al. [40] will be used as they represent more or less the standard for HIAs in air pollution [20, 26]. Next to the all-cause estimate, recommended by the WHO [21], the cause-specific estimate for mortality from cardiopulmonary diseases will be used. This allows being coherent with the estimates for short-term exposure that are also cause-specific. For lung cancer the estimates from Pope et al. [40] will be used for $\mathrm{PM}_{2,5}$. For leukaemia the risk estimate of the WHO Air Quality Guidelines for benzene [41] is used.

Recently a cohort study from a neighbouring country researched the effects of $\mathrm{PM}_{2,5}$ on the same health outcomes as Pope et al. [40]. This Dutch study is not adopted, but is worth mentioning because no association could be found between $\mathrm{PM}_{2,5}$ and the three outcomes assessed here [45].

Where the Dutch cohort study could not find an association with $\mathrm{PM}_{2,5}$, this was not the case for $\mathrm{NO}_{2}$. This allows an assessment of the effects of long-term exposure to $\mathrm{NO}_{2}$ on respiratory mortality.

Special attention is given to infant (respiratory) mortality. For infant mortality, rather than loss in life-years the attributable cases will be calculated, following Kaiser et al. [46]. All risk estimates are taken from Lacasana et al. [38].

\section{Health impact characterization and integration of data}

\subsection{Consequences of epidemiologic restrictions}

The last step in a HIA is to integrate all data in order to quantify the health burden. The many uncertainties related to the risk estimates and the restrictions of epidemiology forces to adopt a twofold strategy in which the health effects are assessed. These strategies are based on the main traditions within HIAs. Depending on the aim of the HIA there's a distinction between a 'conservative' 
and an 'expansive' approach [26]. The 'conservative' approach puts emphasis on ensuring that every impact pathway that is included has been quantified in a reliable way. Estimates are based strongly in the available evidence and it makes no claim to capture the full effects of air pollution. The main purpose is to compare and evaluate the costs of different strategies to reduce pollution. The 'expansive' approach on the other hand, puts priority on the reliability of the quantification as a whole as an estimate of the overall benefits of reducing air pollution. It aims to capture all the effects or air pollution, with a wider coverage of the assumptions and less reliable estimates.

Combining both approaches in one assessment seems - in view of the many health effects for PM, benzene, ozone and $\mathrm{NO}_{2}$ - preferable. In a first phase we will adopt the first 'conservative' tradition, as our aims resemble those of comparing different policy scenarios to reduce air pollution levels and their health impacts. This to establish a solid base for the second strategy in which we will adopt the more 'expansive' approach. In the latter concentration-response functions will be used for which there is good evidence of effect, but a weakness at some point in the impact pathway, e.g. where either toxicological or epidemiologic research fails to deliver certainty on how an impact is to be understood, while the impact itself is undisputed.

Related to the pollutants assessed, this means that a step-wise approach has to be applied (Figure 1), where all pollutants are assessed in descending order of certainty (PM $>$ Benzene $>$ Ozone $>$ Nitrogen dioxide). This hierarchy has to be seen in light of the absence of risk estimates for traffic air pollution and the question which air pollutant is the best indicator for traffic air pollution. Recently $\mathrm{NO}_{2}$ is seen as a better surrogate for the health effects of transport than PM $[21,45,48]$. However uncertainty remains as it is not clear whether $\mathrm{NO}_{2}$ is really a better indicator for traffic pollution or whether there is a confounding effect [29]. The results of the individual pollutants however cannot be added together as this would lead to overestimation [24].

\subsubsection{The conservative strategy}

As the main goal of this HIA resembles most the 'conservative' approach, this was adopted as the first strategy. The conservative tradition is characterized by using the 'at least' approach [23], which consistently selects methodological assumptions in a way to get an impact 'at least' attributable to air pollution, such as calculating the health effects from a baseline frequency - a derived baseline incidence from a situation without pollution- and using an additive instead of multiplicative risk function [3, 24]. These methods are adopted here as well.

Assuming that the relation between particles and benzene on health is causal, major uncertainties arise from the selection of the risk estimate and the methods to measure the concentrations. However by adopting the 'at least' approach, the influence of these are minimized as much as possible [24,47], by selecting only concentration-response functions that are well established and limiting the health effects to those from PM and benzene, a known carcinogen. 


\subsubsection{The 'expansive' strategy}

The second strategy allows a more comprehensive view on the health effects of air pollution. In this strategy the effects of ozone and $\mathrm{NO}_{2}$ will be assessed, together with all age-specific health effects. Ozone is not adopted in the first strategy as the impact on health is not fully established yet, especially regarding the moderate climate in Flanders. For $\mathrm{NO}_{2}$ it is clear that the health effects of $\mathrm{NO}_{2}$ are independent or either correlates with the complex mixture of traffic exhaust. And the age-specific effects are not adopted in the first strategy, because of the many uncertainties that remain in many associations between a particular age and a specific health effect [7]. A sensitivity analysis will be part of the second strategy as well. These alternative analyses provide an insight on how the different decisions and assumptions affect the eventual impact and quantify the many uncertainties associated with HIAs.

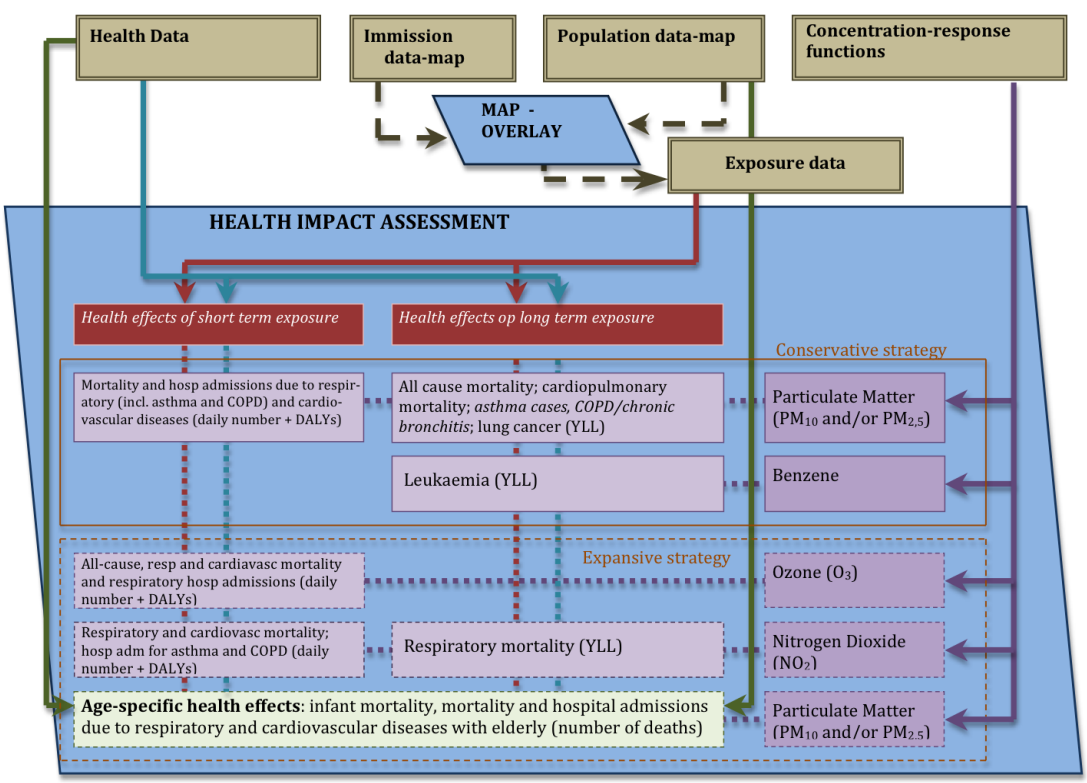

Figure 1: Data sources, processing and expected outcomes.

\subsection{Integration of data into GIS}

To evaluate the health impact of the exposure to air pollution, the exposure estimates have to be linked to data on the current health burden and demographic data. Using a GIS it is possible to integrate these data, to export them to calculation sheets and to visualize them geographically [49]. Maps are valuable tools in risk assessment, because of their ability to explore (spatial) changes in disease patterns associated with air pollution exposure [50].

However there is a difference in the level of detail between concentration data and health data. Exposure data are provided for every census tract, but health 
data are not. Mortality data are available for each municipality and hospital admission data are only available at the district level. Therefore depending on the health outcome results will be presented on either commune or district level.

\section{Discussion}

Current methods of HIA are not yet capable of dealing with recent evolutions in exposure assessment. In this paper preliminary answers are formulated to these evolutions. As it is not yet possible to take advantage from the newly developed individual exposure concentrations, this HIA will still use ambient concentrations, but on a detailed geographical level. To counter the problem of trafficrelated pollution a stepwise approach is adopted in which every pollutant, which is related to traffic, is assessed. Particulate matter and benzene are taken as the main pollutants, based on their robust associations with health. Ozone and nitrogen dioxide are assessed through their relationship with traffic exhaust, but as their associations with health are still troubled with uncertainties, they are not added in the core analysis.

However, real answers should come from new epidemiologic research in finding risk estimates for traffic exhaust and individual exposure concentrations. HIAs allow governments to gain insight on the health impact of their mobility patterns. However if governments want to invest in performing HIAs, they should also invest in epidemiology. Up to this date to many barriers exist in gaining detailed data on health, because of confidentiality issues, which hinders a fast development of epidemiology, especially when calculating risk estimates for individual exposure.

\section{References}

[1] Dumont, G., Fierens, F., Torfs, R., et al., Luchtverontreiniging en verkeer. Welke rol speelt verkeer in de stof- en ozonproblematiek? Milieurapport Vlaanderen MIRA-T 2005. Lannoo: Leuven, pp. 115 - 128, 2005.

[2] Fierens, F., Dalende NOx emissies - stagnerende NO2 concentraties in stedelijke omgeving: wat is er aan de hand? IRCEL-VMM, pp. 9, 2008.

[3] Künzli, N., Kaiser, R., Medina, S., et al., Public-health impact of outdoor and traffic-relayed air pollution: a European assessment. The Lancet, 356, pp. 795-801, 2000.

[4] Forsberg, B. Johansson, C., Segerstedt, B. et al., Predicted air pollution related health impacts of congestion pricing in Stockholm - A local assessment. Institute for Risk Assessment Sciences, University of Utrecht: Utrecht, airnet.iras.uu.nl/resource/posters/rome/airnet_poster36_b_forsberg .pdf

[5] Forsberg, B., Hansson, H-C. Johansson, C. et al., Comparative Health Impact Assessment of local and Regional Particulate Air Pollutants in Scandinavia. Ambio, 34(1), pp. 11-19, 2005.

[6] WHO, Health Effects of Traffic-Related Air Pollution. World Health Organization Regional Office for Europe: Copenhagen, 2005. 
[7] Pope, C.A. III and Dockery, D.W., Health Effects of Fine Particulate Air Pollution: Lines that Connect. J Air \& Waste Manage Assoc, 56, pp. 709742, 2006.

[8] Nemmar, A., Hoylaerts M.F., Hoet P.H. \& Nemery B., Possible mechanisms of the cardiovascular effects of inhaled particles: systemic translocation and prothrombotic effects. Toxicol Lett, 149(1-3), pp. 243-53, 2004

[9] Eastwood, P., Particulate Emissions from Vehicles. John Wiley \& Sons Ltd.: West Sussex, 2008.

[10] Levy, J., Carrothers, T., Tuomisto, J. et al., Assessing the Public Health Benefits of Reduced Ozone Concentrations. Environmental Health Perspectives, 109(12), pp. 9-20, 2001

[11] Samoli, E., Aga, E., Touloumi, G. et al., Short-term effects of nitrogen dioxide on mortality: an analysis within the APHEA project. Eur Resp Journal, 27(6), pp. 1129-1137, 2006.

[12] Kaiser, J., How dirty air hurts the heart. Science, 307, pp. 1858-1859, 2005.

[13] Van Larebeke, N. \& De Bont, R., Gezondheidseffecten van benzeen. Rapporten van het Steunpunt Milieu en Gezondheid, 10, 2006. www.milieu-en-gezondheid.be/rapporten/benzeen.pdf

[14] Sandström, T., Health effects of particles from motor engine exhaust and ambient air pollution, 2009, www.hepmeap.org/en-us/dept_1.html

[15] WHO, Health relevance of particulate matter from various sources. Report on a WHO Workshop, Bonn, 26-27 march 2007. World Health Organization Regional Office for Europe: Copenhagen, 2007.

[16] Hoek, G., Brunekreef, B., Goldbohm, S., et al., The association between mortality and indicators of traffic-related air pollution in a Dutch cohort study. Lancet, 360, pp. 1203-1209, 2002.

[17] Janssens, D., Powerpoint-presentation, Activiteitengebaseerde transportmodellen, Universiteit Hasselt, 2008.

[18] Beckx, C., Arentze, T., Int Panis, L. et al., Assessing Activity-Related Vehicle Emissions through an Integrated Activity-Based Modelling Framework. International Congress on Environmental Modelling and Software, pp. 1177-1186, 2008.

[19] Beckx, C., Int Panis, L., Arentze, T. et al., A dynamic activity-based modelling approach to evaluate exposure to air pollution: methods and application to a Dutch urban area. Environ Impact Assess Rev, doi:10.1016/j.eiar.2008.10. 001, 2008.

[20] VMM, Lozingen in de lucht 1990-2007. Vlaamse Milieumaatschappij, 2008. www.vmm.be/publicaties/lozingen_2007.pdf\#page $=75$

[21] WHO, Quantification of the Health Effects of Exposure to air Pollution. Report of a WHO Working Group. WHO Regional Office for Europe: Bilthoven, 2001.

[22] Anderson, H.R., et al., Meta-analysis of time-series studies and panel studies of particulate matter (PM) and ozone (O3). Report of a WHO task group. WHO Regional Office for Europe, Copenhagen, 2004. 
[23] Medina, S., Boldo E. et al., APHEIS, Health Impact Assessment of Air Pollution and Communication Strategy. Third Year Report. Institut de Veille Sanitaire: Saint-Maurice; 2004.

[24] Künzli, N., Kaiser, R., Medina, S., et al., Health Costs due to Road Trafficrelated Air Pollution. Air Pollution Attributable Cases, Technical Report on Epidemiology. Bern, 1999.

[25] Bickel, P. \& Friedrich, R., ExternE, Externalities of Energy. Methodology 2005 update. Directorate-General for Research Sustainable Energy Systems: Luxemburg, 2005.

[26] Hurley, F., Hunt, A., Cowie, H., et al., Methodology Paper (Volume 2) for Service Contract for carrying out cost-benefit analysis of air quality related issues, in particular in the clean air for Europe (CAFE) programme. AEA Technology Environment: Oxon, 2005.

[27] Sanderson, E. \& Hurley, F., Air pollution and the risks to human health risk and health impact assessment. Institute for Risk Assessment Sciences, University of Utrecht: Utrecht, 2004. http://airnet.iras.uu.nl/products/ pdf/airnet_wg3_toxicology_report.pdf

[28] Pope, C.A., Richard, T., Burnett, R.T., et al., Cardiovascular Mortality and Long-Term Exposure to Particulate Air Pollution: Epidemiologic Evidence of General Pathophysiological Pathways of Disease. Circulation, 109, pp 71-77, 2004.

[29] Analitis, A., Katsouyanni, K., Dimakopoulou, K. et al., Short-Term Effects of Ambient Particles on Cardiovascular and Respiratory Mortality. Epidemiology, 17(2), pp. 230-233, 2006.

[30] Le Tertre, A., Medina, S., Samoli, E., et al., Short-term effects of particulate air pollution on cardiavascular diseases in eight European cities. Journal of Epidemiol Community Health, 56, pp. 773-779, 2002.

[31] Atkinson, R., Anderson, H.R., et al., Analysis of all-age respiratory hospital admissions and particulate air pollution within the Apheis programme. In: Medina, S., Boldo E. et al., APHEIS, Health Impact Assessment of Air Pollution and Communication Strategy. Third Year Report. Institut de Veille Sanitaire: Saint-Maurice, pp. 125-130, 2005.

[32] Atkinson, R., Anderson,H.R., et al., Acute Effects of Particulate Air Pollution on Respiratory Admissions. Am J Respir Crit Care Med, 164, pp. 1860 - 1866, 2001.

[33] Gryparis, A., Forsberg, B., Katsouyanni, K, et al., Acute Effects of Ozone on Mortality from the "Air Pollution and Health: A European Approach" Project. Am J Respir Crit Care Med, 170(10), pp. 1080-1087, 2004.

[34] Spix, C., Anderson, H.R., Schwartz, et al., Short-term effects of air pollution on hospital admissions of respiratory diseases in Europe: a quantitative summary of APHEA study results. Archives of Environmental Health, 53(1), pp. 54-64, 1998.

[35] Sunyer, J., Spix, C., Quénel, P., et al., Urban air pollution and emergency admissions for asthma in four European cities: the APHEA Project. Thorax, 52, pp. 760-765, 1997. 
[36] Anderson, H.R., Spix, C., Medina, S., et al., Air pollution and daily admissions for chronic obstructive pulmonary disease in 6 European cities: results from the APHEA project. European Respiratory Journal, 10, pp. 1064-1071, 1997.

[37] Zanobetti et al., The Temporal Pattern of Respiratory and Heart Disease Mortality in Response to Air Pollution. Environmental Health Perspectives, 111(9), pp. 1188-1193, 2003.

[38] Lacasana, M., Esplugues, A. \& Ballester, F., Exposure to ambient air pollution and prenatal and early childhood health effects. European Journal of Epidemiology, 20, pp. 183-199, 2005.

[39] Beelen, R., Hoek, G., van den Brandt, P., et al., Long-Term Effects of traffic-Related Air Pollution on Mortality in a Dutch Cohort. Env Health Perspectives, 116(2), pp. 196-202, 2008.

[40] Pope, C.A., Burnett, R., Thun, M., et al., Lung cancer, cardiopulmonary mortality, and long-term exposure to fine particulate air pollution. JAMA, 287(9), pp 1132-1141, 2002.

[41] WHO, Air Quality Guidelines for Europe. Second Edition. WHO Regional Publications, European Series, No. 91, 288, 2000.

[42] WHO, Health risks of ozone from long-range transboundary air pollution. WHO Regional Office for Europe: Copenhagen, 2008.

[43] Dockery, D., Pope, C.A., Xiping, X., et al., An association between air pollution and mortality in six US cities. N Engl J Med, 329(24), pp. 1753 1759, 1993.

[44] Laden, F., Schwartz, J., Frank, E. et al., Reduction in Fine Particulate Air Pollution and Mortality. Am J Respir Care Med, 173, pp. 667-672, 2006.

[45] Beelen, R., Hoek, G., van den Brandt, P., et al., Long-Term Exposure to Traffic-Related Air Pollution and Lung Cancer Risk. Epidemiology, 19(5), 702-710, 2008.

[46] Kaiser, R., Romieu, I., Medina, S., et al., Air pollution attributable postneonatal infant mortality in US metropolitan areas: A risk assessment study. Environmental Health: A global access science source, 3, pp. 4, 2004.

[47] Ballester, F., Medina, S., Boldo, E. et al., Reducing ambient levels of fine particulates could substantially improve health: a mortality impact assessment for 26 European cities. J Epidemiol Community Health, 62, pp 98-105, 2008.

[48] Van Roosbroeck, S., Li, R., Hoek, G. et al., Traffic-related outdoor air pollution and respiratory symptoms in children: the impact of adjustment for exposure measurement error. Epidemiology, 19(3), pp. 409-16, 2008.

[49] Mindell, J. and Barrowcliffe, R., Linking environmental effects to health impacts: a computer modelling approach for air pollution. J Epidemiol Community Health, 59, pp. 1092-1098, 2005.

[50] Jarup, L., Health and Environment Information Systems for Exposure and Disease Mapping, and Risk Assessment. Env Health Perspec, 112(9), pp. 995-997, 2004. 